\title{
Una ventana indiscreta Espacio público y privado en la revista La Chiva
}

\author{
Claudio Aguilera y Hugo Hinojosa
}

Recibido: 15.05.2021 — Aceptado: 09.06.2021

\section{Titre / Title / Titolo}

Une fenêtre indiscrète : espace public et privé dans le magazine La Chiva An indiscreet window: public and private space in La Chiva magazine Una finestra indiscreta: spazio pubblico e privato nel magazzino La Chiva

\section{Resumen / Résumé / Abstract / Riassunto}

El final de la década del sesenta marca un momento de profundos cambios en la sociedad chilena. Sumado al incipiente proceso de polarización política, la ciudad de Santiago comienza a crecer desmesuradamente, al igual que su población, sin una clara planificación de esta. Mientras, este proceso de descontrolado desarrollo urbano fue desplazando a comunidades enteras, quienes se ven obligadas a aglutinarse en improvisadas viviendas en la periferia de la ciudad, construyendo poblaciones que se multiplican como callampas en los terrenos eriazos. En este contexto emerge La Chiva, revista de humor fundada en 1968 por cuatro jóvenes dibujantes chilenos, la cual a través de secciones como «Santiago tal cual» o «De La Vega a Vitacura», va asumiéndose como un muestrario detallado de la ciudad en transformación. De este modo, este artículo se centrará en explorar un poco más en profundidad algunas de sus historias más recordadas, tales como «Lo Chamullo» y, en particular, «La ventana indiscreta», creación del reconocido dibujante nacional Hervi, en donde podremos reconocer el carácter renovador de sus trabajos en el campo de la historieta chilena. El coqueteo constante con la exploración formal, el diálogo directo con la contingencia social, el juego con el lenguaje de la historieta, y la ciudad leída como una viñeta, serán algunos de los aspectos a discutir. Asimismo, a la luz de recientes investigaciones sobre las relaciones entre arquitectura e historieta, el presente trabajo intentará dar cuenta de las particularidades de esta serie, y formular una lectura de ella en el marco del contexto social, político y urbano de la época, particularmente en la ciudad de Santiago de Chile.

La fin des années 60 marque une période de profonds changements dans la société chilienne. En plus du processus naissant de polarisation politique, la ville de Santiago a commencé à croître de manière disproportionnée, tout comme sa population, sans planification claire. Pendant ce temps, ce processus de développement urbain incontrôlé déplaçait des communautés entières, qui étaient obligées de se regrouper dans des habitations de fortune à la périphérie de la ville, constituant des populations qui se multipliaient comme huttes sur des terres non cultivées. C'est dans ce contexte qu'apparaît La Chiva, un magazine d'humour fondé en 1968 par quatre jeunes dessinateurs chiliens, qui, à travers des rubriques telles que "Santiago telle qu'elle est" ou "De La Vega à Vitacura", est assumé comme un échantillon détaillé de la ville en transformation. Ainsi, cet article s'attachera à explorer un peu plus en profondeur certaines de ses histoires les plus mémorables, comme "Lo Chamullo" et, en particulier, "La ventana indiscreta", création du célèbre dessinateur national Hervi, où l'on peut reconnaître le caractère rénovateur de son œuvre dans le domaine de la bande dessinée chilienne. Le flirt constant avec l'exploration formelle, le dialogue direct avec la contingence sociale, le jeu avec le langage de la bande dessinée, et la ville lue comme un dessin animé, seront quelques-uns des aspects abordés. Par ailleurs, à la lumière des recherches récentes sur la relation entre l'architecture et la bande dessinée, cet article tentera de rendre compte des particularités de cette série, et d'en formuler une lecture dans le contexte social, politique et urbain de l'époque, notamment dans la ville de Santiago du Chili.

The end of the sixties marks a moment of deep changes in Chilean society. Added to the incipient process of political polarization, the city of Santiago begins to grow disproportionately, with no clear planning, and so does the overall number of the city's population. At the same time, the process of uncontrolled urban development displaced entire communities, who were forced to gather in makeshift homes at the city's outskirts, forming communities which proliferated in shanties on the vacant lands. In this context, the humor magazine La Chiva was founded in 1968 by four young Chilean cartoonists. Through its different sections, such as «Santiago tal cual» or «De La Vega a Vitacura», the magazine became a detailed showcase of the city in transformation. The article will focus on an exploration of some of the most memorable stories, such as "Lo Chamullo" and, especially, "La Ventana indiscreta", creations of the renowned local artist Hervi, which allow an acknowledgment of the innovative character of the artist's work in the field of Chilean comics. The constant flirtation with formal exploration, the direct dialogue with social contingency, the interplay with the language of comics, and the city read as a comic strip, are some of the aspects discussed in the text. Likewise, in the light of recent research on the relationships between architecture and comics, the article also aims to account for the particularities of such series and to formulate a reading within the framework of the social, political, and urban context of the time, particularly in the city of Santiago de Chile. 
La fine degli anni sessanta segnò un periodo di profondi cambiamenti nella società cilena. La città di Santiago viveva un incipiente processo di polarizzazione politica e, in aggiunta, cominciò a crescere in modo sproporzionato, senza una pianificazione chiara, mentre aumentava drasticamente il numero di abitanti. Tale processo di sviluppo urbano incontrollato dislocò intere comunità, che furono costrette a concentrarsi in abitazioni di fortuna alla periferia della città, formando comunità che si moltiplicarono come baraccopoli su terreni incolti. In questo contesto emerge La Chiva, una rivista umoristica fondata nel 1968 da quattro giovani fumettisti cileni, che attraverso sezioni come "Santiago tal cual " o "De La Vega a Vitacura", si plasma come una mostra dettagliata della città in trasformazione. Questo articolo si concentra sull'esplorazione di alcune delle sue storie più ricordate, come "Lo Chamullo" e, in particolare, "La ventana indiscreta", creazioni del rinomato fumettista Hervi; in esse possiamo riconoscere il carattere innovatore del suo lavoro nell'ambito del fumetto cileno. Il flirt costante con l'esplorazione formale, il dialogo diretto con la contingenza sociale, il gioco con il linguaggio dei fumetti, e la città stessa letta come un fumetto, sono alcuni degli aspetti discussi nel testo. Inoltre, alla luce delle recenti ricerche sul rapporto tra architettura e fumetto, l'articolo si propone di fornire un resoconto delle particolarità di tali serie, e di formularne una lettura nel contesto sociale, politico e urbano dell'epoca, in particolare nella città di Santiago del Cile.

\section{Palabras clave I Mots-clé I Key words I Parole chiave}

La Chiva, cómic, ciudad.

La Chiva, bande dessinée, ville.

La Chiva, comics, city.

La Chiva, fumetto, città.
Cuando en 1968 se funda la revista de humor La Chiva, Chile vive un periodo de profundos cambios sociales y políticos, incluyendo transformaciones urbanas impulsadas por sectores marginalizados que se organizan para resolver comunitariamente sus problemas de vivienda en Santiago, una ciudad marcada por la segregación, el crecimiento demográfico explosivo y la falta de planificación. La valoración de estos sectores y la visibilización de nuevas formas de sociabilización en el espacio público fueron ejes de la publicación a través de series como «Lo Chamullo»y «La ventana indiscreta», dibujada por el artista Hernán Vidal (Hervi), las cuales dieron cuenta del interés por explorar el lenguaje de la historieta por medio, en este caso, de una visualización panóptica de la urbe. A través de este artículo se intentará dar cuenta de las particularidades de esta serie y formular una lectura de ella en el marco del contexto social, político y urbano de la época, particularmente en la ciudad de Santiago de Chile. Para ello, se entregará un breve contexto, tanto de la situación urbana del período, como de la creación y desarrollo de la revista La Chiva. Posteriormente, nos centraremos en la figura de Hervi, lo que permitirá comprender la creación de «La ventana indiscreta», para finalmente abordar una reflexión teórica sobre la obra, centrada en como la ciudad es presentada como una gran viñeta cuya estructura se construye a partir de elementos arquitectónicos (calles, ventanas, fachadas, mobiliario) que organizan la narración, y permite discutir aspecto temporales y espaciales dentro de la historieta.

\section{Hacia la ciudad de masas}

A partir de los años 30 en la ciudad de Santiago se da inicio a un importante proceso de desarrollo demográfico y urbano, impulsado por la creciente migración rural producto de la crisis de 1929, la consolidación de la clase media y el posterior proceso de industrialización. Según el historiador Armando de Ramón, en su libro Santiago de Chile (1541-1991): Historia de una sociedad urbana, entre 1940 y 1970 la población aumentó de 952.075 a 2.861.900 habitantes. La apremiante necesidad de crear 
nuevas viviendas gatilló un crecimiento inorgánico de la urbe y el nacimiento de nuevas poblaciones en la periferia de la ciudad. Esta situación, sumada a la búsqueda de la élite de espacios exclusivos, la ampliación del parque automotriz y la modernización de los sistemas de transporte público durante el periodo redibujó de manera radical la fisonomía de una ciudad que durante cuatros siglos había conservado su esencia colonial.

Para De Ramón(2018), quien ha denominado a esta etapa «la ciudad de las masas», estos cambios habrían alcanzado su máxima intensidad en las décadas de 1960 y 1970 y, a largo plazo, condujeron a Santiago a una realidad urbana muy diferente a la que tenía previamente. En el marco de un proyecto desarrollista y el intento por mejorar las condiciones de los grupos más desfavorecidos, durante este periodo y especialmente a partir de la elección de Eduardo Frei en 1964 el Estado reaccionó a través de instituciones cuyo objetivo era crear viviendas dignas, aumentar la densidad y promover la planificación urbana. De este modo en 1953 nació la Corporación de la Vivienda (CORVI) ${ }^{1}$ y la Ley General de Construcciones y Urbanización; en 1960 se dictó un nuevo Plan Intercomunal para Santiago; en 1965 se fundó el Ministerio de Vivienda y Urbanismo, y en 1968 se dictó la Ley de juntas de vecinos y organizaciones comunitarias.

Paralelamente, se iniciaron importantes obras públicas que buscaban hacer más eficiente la conectividad, tales como la creación y ensanche de grandes avenidas con motivo de celebración del mundial de fútbol de 1962, la construcción de dos importantes conjuntos arquitectónicos compuestos por edificios y locales comerciales (Torres de Tajamar y Remodelación San Borja), la organización de nuevas urbanizaciones o la primera etapa del tren subterráneo en la ciudad.

Durante el periodo estudiado, la CORVI tendrá un rol central en la búsqueda de soluciones habitacionales, tanto para ciudadanos de escasos recursos, como para la clase media, en la que se vislumbra un intento real por mejorar las condiciones de la población a través de proyectos de gran envergadura, y con especial atención a la relación entre el espacio público-espacio privado y, según sus propios estatus, «la convivencia social». Algunos ejemplos destacados son la Remodelación República (1964), Villa presidente Frei (1965) y la Villa Olímpica (1961-1967).

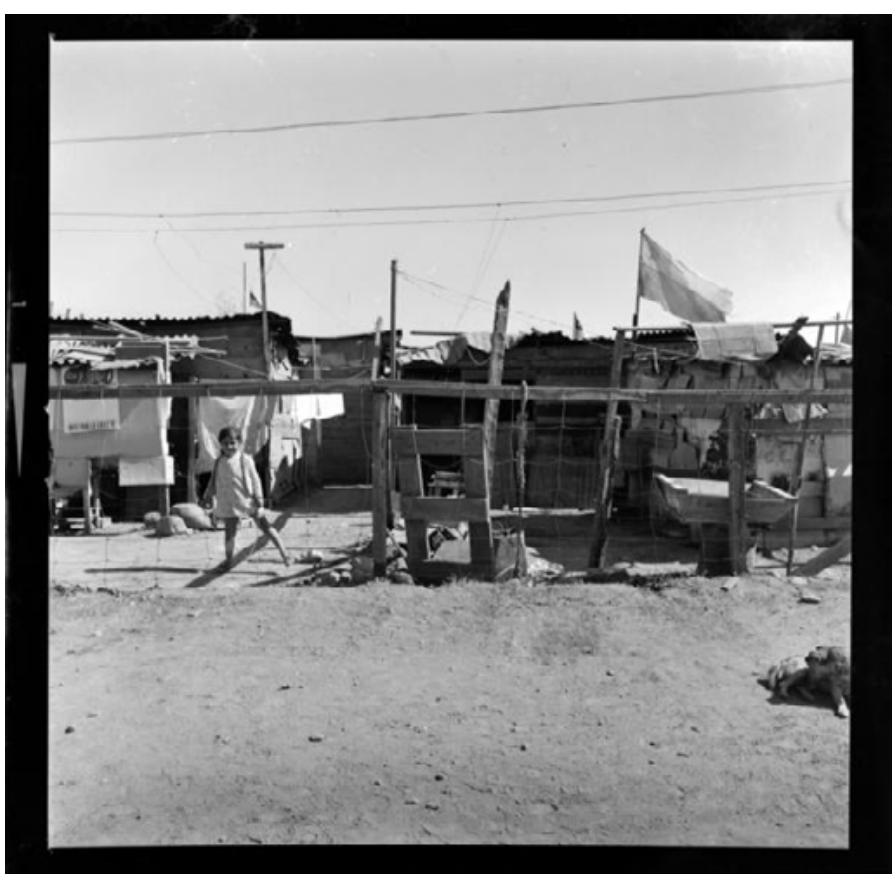

Fig.1 Fotografía de una población «callampa», tomada por Armindo Cardoso en 1971

Pese a estas iniciativas, la urbe fue incapaz de satisfacer la demanda de viviendas, por lo que a partir de los años 50 tuvieron lugar una serie de ocupaciones ilegales de terrenos, llamadas «tomas», que más tarde derivaron en grandes asentamientos precarios conocidos como poblaciones callampas ${ }^{2}$ (Fig.1), proceso que se agudizó durante la década siguiente. En 1966 el 12\% de la población de Santiago vivía en condiciones de precariedad habitacional, cifra que para 1970 alcanzó el 16\% (Espinoza, 277).

Frente a la imposibilidad de adquirir o arrendar viviendas, la carencia de servicios y equipamiento básicos, la falta de medios de transporte, y de condiciones mínimas de salubridad y respuestas oportunas del Estado, los pobladores aptaron por la autoconstrucción, la organización comunitaria y las movilizaciones, lo que derivaría en una fuerte identidad, conciencia colectiva y espíritu autárquico. En palabras de Vicente Espinoza,

\footnotetext{
La denominación «callampas» hace referencia al rápido crecimiento y proliferación de los hongos, así como a la precariedad de las construcciones, que en muchos casos se realizaban con materiales de desecho.
} 
«el entorno, el hábitat, se constituyó en una categoría de identidad: los pobladores se identificaban a sí mismos como habitantes pobres de una zona de Santiago» (Espinoza, 260).

Tal como señalan los historiadores Gabriel Salazar (2012) o Mario Garcés (2019), a contar de los años 60 este grupo se transformó en una activa fuerza política que sería relevante en la elección del demócrata cristiano Eduardo Frei en 1964 y crucial en el caso del socialista Salvador Allende en 1970. Este último llevó a cabo significativos programas de construcción de viviendas, en las que se consideraban tanto la urbanización como el equipamiento social, además de una política de edificación en altura, junto con la participación de las y los pobladores en las decisiones que involucraban sus casas y entornos. Particular importancia tuvo la Corporación de Mejoramiento Urbano (CORMU), dirigida por el arquitecto Miguel Lawner, a cargo de la ejecución de conjuntos habitacionales en Santiago y Valparaíso, y que también participó en la planificación del edificio de la UNCTAD III, inaugurado en 1972.

Este proceso de política pública habitacional fue violentamente interrumpido tras el golpe militar de 1973, momento en el cual se inició la erradicación de los campamentos y el traslado forzoso de miles de familias hacia lugares periféricos de la ciudad. El resultado fue la destrucción de la identidad comunitaria y las organizaciones de base, segregación social, hacinamiento y desigualdad en el acceso a salud, trabajo y educación, incrementado por la adopción de un modelo de economía neoliberal que provocó grandes bolsones de pobreza, marcados por el narcotráfico, la delincuencia y la estigmatización hasta el presente.

Asimismo, la grave crisis económica que afectó a Chile en 1982 profundizó la precaria situación de miles de familias santiaguinas, que frente a la imposibilidad de adquirir e incluso arrendar viviendas propias se instalaron en campamentos o en las casas de cercanos, fenómeno que se hizo conocido como «allegados», y debieron sobrevivir a la cesantía a través de «ollas comunes» o trabajos esporádicos. Su realidad, sumada a la fuerte represión impuesta por el gobierno militar, fue el germen de una serie de multitudinarias protestas que desembocarían en el plebiscito de 1988 y el retorno de la democracia.

Para Armando de Ramón, este movimiento permitió una reapropiación de las calles y espacios simbólicos de la ciudad, al tiempo que dio cuenta de la reorganización política de las poblaciones emblemáticas fuertemente castigadas por la dictadura:

Estas protestas constituyeron el «hecho urbano» más relevante de los últimos tiempos en la historia de Santiago de Chile, ya que esta manifestación recorrió toda el área urbana y comprometió a todas las clases sociales» y «la convirtieron en un símbolo histórico de cara a la posteridad (257).

Sin embargo, estos problemas de inequidad social persisten hasta el día de hoy, en una sociedad altamente segmentada y que relega a sus pobladores más pobres a los límites de la ciudad, empujándoles literal y simbólicamente a la pobreza y la exclusión.

\section{La Chiva. Proyecto artístico horizontal}

Es mediados de 1968 y el país está en un ambiente de creciente efervescencia política. Son los últimos años del gobierno Demócrata cristiano de Eduardo Frei Montalva, y a la vuelta de la esquina se encontrará el futuro gobierno de la Unidad Popular, conducido por Salvador Allende, quien llegará al poder no sin resistencia de variados sectores. En ese contexto emergerá $L a$ Chiva, proyecto sui generis para el medio local, en donde cuatro jóvenes dibujantes desplegaron toda su creatividad y talento haciendo eco de las diferentes inquietudes sociales y políticas de la época.

Su origen se remonta a una serie de conflictos editoriales. Alberto Vivanco trabaja como subdirector de la revista para jóvenes Ritmo, donde además oficiaba como dibujante. Luego de diferencias de criterios con María del Pilar Larraín, la otra directora, en 1967 Vivanco decide tomarse un año sabático. Él mismo señala, «yo me había vuelto cada vez más intransigente en 


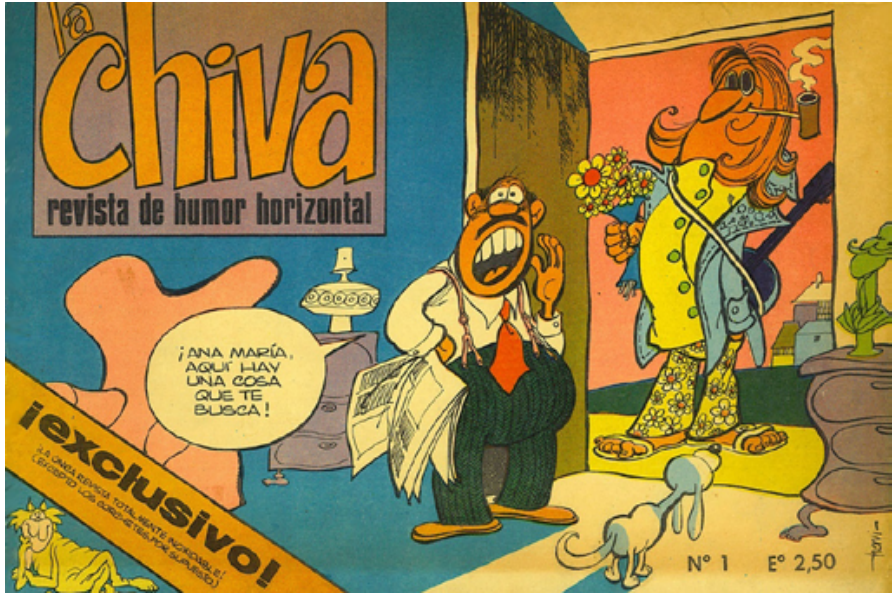

Fig.2 Portada correspondiente al número 1 de la publicación en julio de 1968

la defensa de los «rotos» ${ }^{3}$ y sus artistas populares. En eso, nuestras apreciaciones eran totalmente divergentes e irreconciliables.» ${ }^{4}$ Este tiempo le permitirá hacerse cargo de la dirección de la revista de humor para adultos, El Pingïino, luego de su paso a Editorial Lord Cochrane. Es en aquella revista donde trabajará junto a los artistas que conformarán el equipo central de la futura publicación: Jorge Vivanco (hermano de Alberto), alias Pepe Huinca, Hernán Vidal, alias Hervi, y Pepe Palomo.

El paso de Alberto por El Pingüino fue breve y significó la salida de este último de sus otros proyectos, pero también con ello logró recibir una compensación monetaria que permitió financiar el inicio de una nueva revista: La Chiva ${ }^{5}$. Es así como los cuatro amigos deciden embarcarse en una aventura absolutamente riesgosa desde el punto de vista editorial. Para su número 1 (fig. 2) realizan un tiraje de 40.000 ejemplares, el cual financian de su propio bolsillo.

En Chile el término «roto» hace referencia a un sujeto popular, empobrecido. El concepto, de larga data, ha sufrido diversas interpretaciones en la historia nacional, desde la figura heroica del soldado voluntario durante la Guerra del Pacífico en el siglo XIX hasta ser incluso usado en sentido despectivo, a modo de insulto hacia otra persona.

4 Texto aparecido en el sitio de difusión de historieta Ergocomics, durante el año 2019.

Una «chiva» es un término coloquial utilizado en Chile para referirse a una excusa verbal que suele ser engañosa o tramposa.

La revista no incorporará mayor información referencial de su publicación, más que el año y número de publicación en sus primeras ediciones. Ya a partir del 4 solo señala numeración, sin ningún otro tipo de indicación temporal.

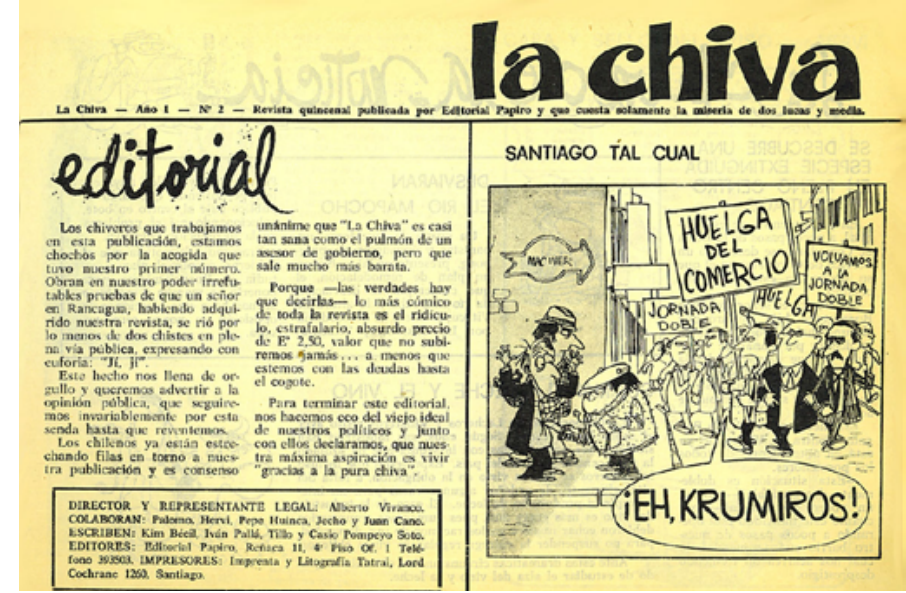

Fig.3 «Santiago tal cual» (año 1, número 2. Sin fecha)

Era un espacio absolutamente independiente y autogestionado, pero que no contaba con una buena distribución. Solo podían confiar en su experiencia previa y en la calidad de sus contenidos. Afortunadamente, esa misma libertad que les brindaba el no contar con casa editorial es la que también la volvió una revista icónica dentro de la historieta y el humor gráfico en Chile.

Bajo el lema «revista de humor horizontal», que acompañará sus primeros números, La Chiva buscará ser un espacio que llegue a todos/as, pero principalmente a aquellos mismos sectores que antes habían sido excluidos y fueron parte de las diferencias ideológicas en la revista Ritmo. Aquella sociedad marginalizada y que pocas veces solía ser representada, en conjunto con una ciudad cada vez más segregada y fracturada, será el centro de la publicación. Es así como en sus páginas emergerán diversas secciones que permitirán realizar una lectura crítica de la sociedad chilena de finales de la década del sesenta. Entre ellas podemos destacar algunas como «Santiago tal cual» (fig.3), la cual acompañaba a la editorial de cada número, mostrando algún aspecto particular de la ciudad. En esta misma línea encontramos «De La Vega a Vitacura» ${ }^{7}$ (fig.4), retrato de la división de clases que se sostiene has-

«La Vega» corresponde al popular barrio donde se encuentra el Mercado de abastos más antiguo de la ciudad. Ubicado en el centro de la ciudad, a un costado del rio Mapocho, actualmente sigue activo y con gran presencia de migrantes que han ingresado recientemente al país. Por otro lado, Vitacura es una comuna situada en la parte alta de Santiago, cercana a la cordillera, y en donde se concentra parte de la población más adinerada del país. 


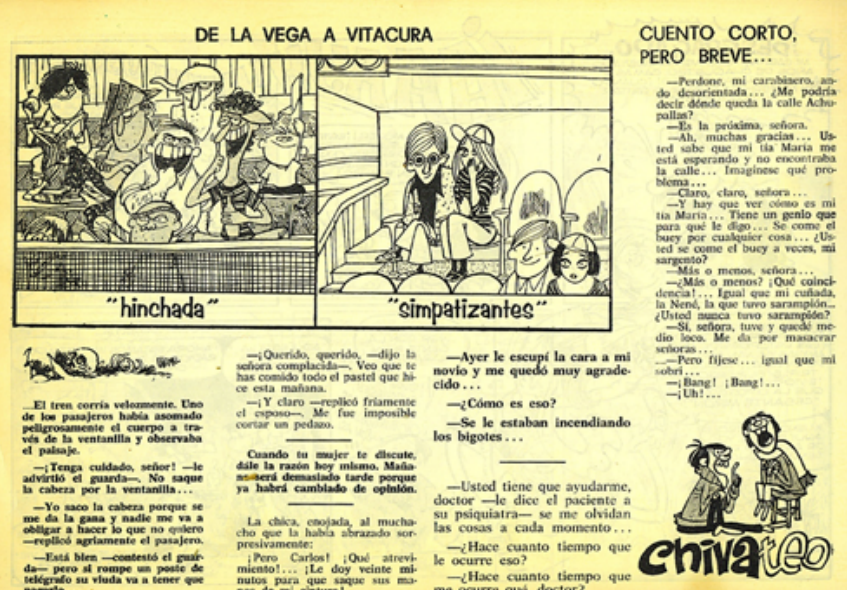

Fig.4 «De La Vega a Vitacura» (año 1, número 3. Sin fecha)

ta el día de hoy, mostrando el contraste de una misma situación entre dos barrios reconocibles en la capital.

Asimismo, la revista constantemente se burlaba de sí misma, de su condición precaria como proyecto, pero también ironizando con las grandes problemáticas sociales que aquejaban al país. Entre los temas relevantes que se desarrollaban habitualmente estaba la desigualdad y la falta de oportunidades. Por ejemplo, en esta página completa aparecida en la revista (fig. 5), el título del texto juega con la expresión «el sueño de la casa propia», que hace referencia al anhelo extendido de la clase media y baja de tener una vivienda de su propiedad. Se reemplaza la palabra «casa» con «tapa», que en Chile se utiliza como una forma coloquial de expresar que no se obtendrá nada. La idea de «hacerle una tapa» a alguien, se acompaña habitualmente del gesto de la imagen, en donde la abertura que se hace con una mano luego es violentamente tapada por la otra, no permitiendo alguna luz o salida.

Esta misma preocupación por la situación de cientos de familias en la ciudad, se verá representada por la que será probablemente su sección más icónica: «Lo Chamullo,

un barrio como el suyo» (fig.6). Con un elenco variopinto de personajes, esta historieta central en la revista mostrará las aventuras y desventuras de una población de escasos recursos que podría ser asimilada a los muchos campamentos habitacionales que emergieron en el período. En particular, «Lo Chamullo» será a la vez un ejemplo del espíritu editorial de la publicación al ser dibujada a ocho manos por los integrantes centrales de La Chiva, en un ejercicio de creación colectiva poco habitual, incluso hasta el día de hoy.

El proyecto seguirá desarrollando sus contenidos pero, a pesar de contar con un buen índice de lectores, sufrirá por mantenerse en pie. Asimismo, irá incorporando colaboradores entre los que se cuentan grandes nombres de la historieta nacional como Nato, Themo Lobos, entre otros. Por otro lado, las preocupaciones políticas de la revista se irán intensificando. El punto de inflexión será el triunfo de la Unidad Popular en 1970. Es en el gobierno del presidente Salvador Allende donde se funda la editorial nacional Quimantú, en la cual Vivanco, Pepe Huinca y Hervi ${ }^{8}$ seguirán traba-

\footnotetext{
Vivanco y Hervi también realizaron labores como editor y director de arte, respectivamente, en otras publicaciones de Quimantú.
}

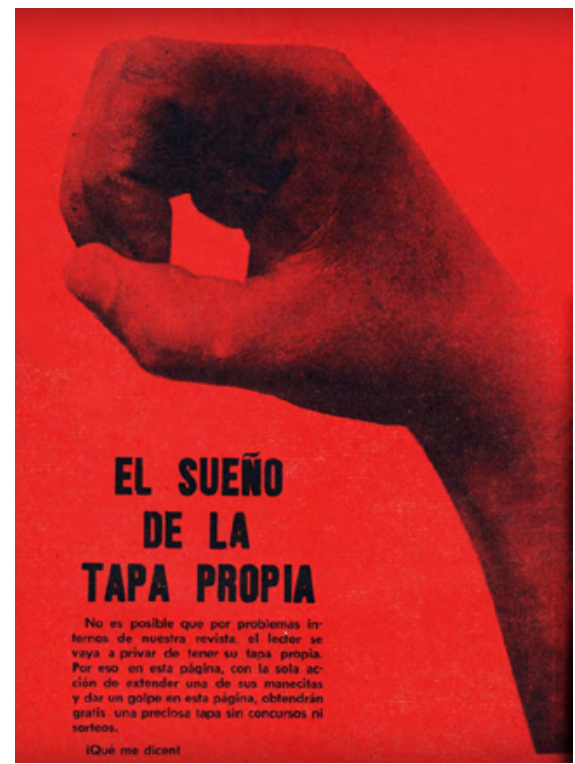

Fig.5 En esta contraportada del número 35 de $L a$ Chiva, se ironiza con la imposibilidad de obtener la vivienda propia (Sin año ni fecha)

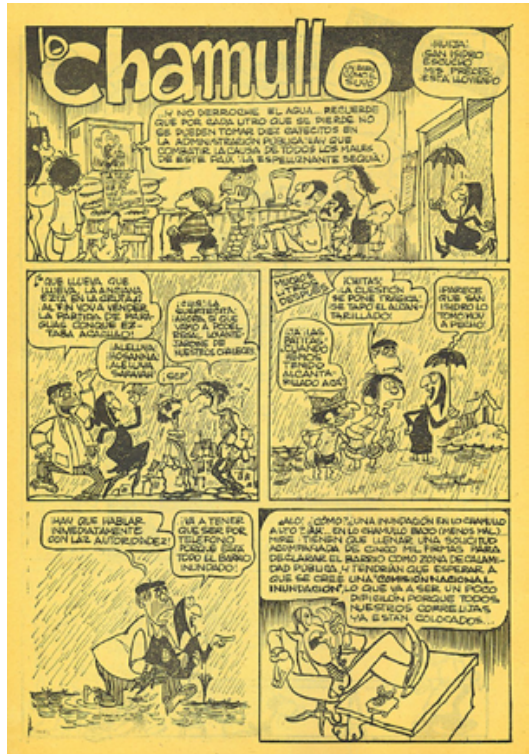

Fig.6 Episodio aparecido en el número 23 (sin año ni fecha). Vemos la problemática de las inundaciones por las lluvias. 
jando juntos en revista La Firme ${ }^{9}$, una publicación de educación popular, cuyo título hace referencia a la expresión coloquial chilena «la firme», que hace alusión a decir la verdad sin adornos, de forma directa, marcando una diferencia con el título de La Chiva. En este nuevo proyecto continuarán abordando temas de interés social como la reforma agraria, la nacionalización del cobre, la burocracia, los monopolios, la prensa, el rol de los obreros y las nuevas políticas en materia de salud, educación y vivienda del Estado. Por su lado, luego de 50 números, la revista La Chiva dejará de existir para dar paso al proyecto más político, pero dejará un legado que hasta el día de hoy es reconocido.

\section{Hervi, arquitectura en viñetas}

Considerado uno de los más importantes dibujantes chilenos, Hernán Vidal Martínez (1943), conocido con el seudónimo de Hervi, ha desarrollado desde finales de los años 50 una prolífica carrera que incluye el diseño editorial, el humor gráfico y la ilustración. Tal como señala el investigador y especialista en historieta y humor gráfico, Jorge Montealegre, esta amplia trayectoria le otorga a Hervi una mirada privilegiada a la vida cotidiana y los procesos históricos del último medio siglo en la sociedad chilena:

Período de sesenta años que acontece en un escenario internacional marcado por la guerra fría que enfrenta las potencias norteamericana y soviética con sus respectivas connotaciones ideológicas, económicas, militares y culturales. El conflicto, situado en la zona de influencia de Estados Unidos, se desarrolló -entre otros- en el campo del imaginario, donde la caricatura política y la historieta tuvieron protagonismo (Montealegre, 7).

Dentro de sus intereses la ciudad, en general, y la arquitectura y el urbanismo, en particular, han tenido un espacio destacado. Esta sensibilidad con el entorno

El nombre de la revista hace referencia a la expresión coloquial chilena «la firme», que hace alusión a decir la verdad sin adornos, de forma directa. Justamente, esto marca una diferencia con el título de La Chiva. tiene profundas raíces biográficas y lo llevaron a seguir la carrera de arquitectura:

Mi padre fue constructor toda su vida. Las casas donde viví las hizo con sus propias manos. Era además un carpintero experto, que incluso fabricaba sus herramientas, en tiempos en que las importaciones eran prohibitivas. Eso, y vivir con mi hermano mayor Luis, artista plástico de los mejores, me dieron un ambiente natural para crecer con esos afanes (Vidal, entrevista) ${ }^{10}$.

Con tan solo nueve años fue becado para asistir a la Escuela Experimental Artística, donde adquirió una sólida formación plástica. En 1958 debutó profesionalmente como dibujante en el diario La Vozy pronto comenzó a trabajar en revista Condorito ${ }^{11}$ junto a su creador René Ríos Boettiger (Pepo), quien se transformó en su maestro.

En 1962 ingresó a la Facultad de Arquitectura de la Universidad de Chile en la cual no solo desde hace más de una década se debatían las principales tendencias a nivel internacional en torno a la ciudad moderna (De Ramón, 2018), también existía una participación activa de docentes y estudiantes en los grandes proyectos de vivienda social que se estaban ejecutando en la época:

La Universidad de Chile, desde luego, era muy progresista. Los temas de Taller, el ramo principal, se enfocaban en objetivos sociales: viviendas, escuelas, hospitales, industrias, etc. La facultad era un hervidero de ideologías, la discusión política era intensa, en esa década previa a las elecciones presidenciales de 1970 (Vidal, entrevista).

Durante sus estudios, el dibujante trabajó en las oficinas de arquitectura de sus profesores en la realización de proyectos y concursos públicos en distintos lugares del país, lo que le permitió comprender en terreno las problemáticas urbanas.

Los cambios que por entonces afectaban a Santiago, tanto a nivel urbanístico, como social y político,

\footnotetext{
10 Las respuestas entregadas a continuación por el autor son parte de una breve entrevista inédita que realizamos, con motivo de este mismo artículo.

Es interesante hacer notar que el personaje de Condorito, creado en 1949, es representante del proceso de migración campo-ciudad iniciado en los años 30 y que gran parte de sus acciones, en especial durante sus primeros años, están motivadas por el hambre, la falta de dinero, la cesantía y la carencia de una vivienda.
} 
no solo estaban dentro del debate académico. Obras de teatro como Los invasores (1963) de Egon Wolff, la película Largo viaje (1967) de Patricio Kaulen, y libros como Guia Humorística de Santiago (1966) de Tito Mundt, encarnaron diversos modos de transmitir el miedo de la burguesía, la desigualdad social a la que estaban sometidas las clases marginadas y el orgullo algo cínico de la clase media, respectivamente, frente a las transformaciones de la época:

Una ciudad está más allá de los planos, mapas, cuadros y estadísticas. Una ciudad tiene un alma y un rostro secreto que está escondido en sus esquinas y que hay que captar cuidadosamente para presentárselo a los extranjeros y turistas de paso. Es mentira que Santiago sea fósil y sin vida. Que no tenga historia ni personalidad. Que sea frío y gris. Que nos aburramos en él. Que no haya nunca nada en sus calles y plazas. Que no se recuerde con nostalgia cuando estamos lejos (Mundt, 8-9) ${ }^{12}$.

Esa mezcla de reivindicación y afecto que se desprende del texto de Mundt puede también encontrarse en la serie de humor gráfico «La ventana indiscreta», nacida en 1967 y publicada en la revista El Pingüino, que como se comentó previamente, era dirigida por entonces por el editor y dibujante Alberto Vivanco, quien buscó renovar la publicación de carácter picaresca incorporando a una nueva generación de historietistas, entre ellos José Palomo y Pepe Huinca, y autores consagrados como los argentinos Oski y el guionista Héctor Germán Oesterheld.

Inspirada en la película de 1954 de Albert Hitchcock, «La ventana indiscreta» unió una crítica visión sobre sobre el desarrollo de la ciudad con un afán por crear situaciones cotidianas llevadas al absurdo. En sus viñetas, muchas de ellas a doble página, tanto horizontales como verticales, confluyen balcones, techumbres, torreones, balaustradas y ornamentos de diferentes épocas y estilos que podría recordar al emblemático barrio París - Londres de Santiago, construido en los años 20 por los arquitectos Ricardo Larraín Bravo y Alberto Cruz Montt, donde conviven propuestas renacentistas, neoclásicas, barrocas y neocoloniales. En sus dibujos también se pueden encontrar referencias a la arquitectura de inspiración victoriana y el eclecticismo del puerto de Valparaíso, y el estilo moderno de mediados del XX que en los años 60 caracterizó emblemáticas construcciones en altura como las Torres de Tajamar y la Remodelación San Borja.

Sin embargo, si bien en los dibujos de Hervi se pueden descubrir ciertos rasgos que hacen referencia a edificaciones existentes, no se trata de una descripción documental como si lo fue en el caso de Lukas ${ }^{13}$, otro dibujantearquitecto fundamental en el humor gráfico chileno. Lo suyo parece ser más un intento de llevar al extremo una «manera» de hacer arquitectura donde la superposición de elementos, la falta de planificación y la improvisación de soluciones da como resultado una ciudad caótica, inhabitable e incoherente, que a momentos se acerca a los dibujos de prisiones imaginarias de Giovanni Battista Piranesi y de los grabados de M. C. Escher. Esta noción de «ciudad collage» o «ciudad patchwork» es reforzada por la inclusión en algunas de las viñetas de imágenes impresas de diferentes orígenes, o por los recuerdos del autor:

\begin{abstract}
Mi padre improvisaba todo, la distribución poco funcional de los ambientes, la ausencia de un criterio estructural, la mezcla de materiales de todo tipo, junto con un creativo uso de ellos. Aún recuerdo sus patchwork de pavimentos con saldos de baldosas compradas en un remate, similares a las frazadas que hacía mamá con restos de géneros que había guardado. Tal vez esa deba ser la esencia de la arquitectura, una mezcolanza de ideas concretizadas según los recursos a la mano, sin perder de vista el uso final de la obra. Un camino a recorrer con variables creativas que van modificando el proyecto hasta su culminación. (Vidal, entrevista).
\end{abstract}

Esta idea sobre la arquitectura se transforma en «La ventana indiscreta» en una metodología de trabajo que le permite construir las viñetas a través de una suma progresiva de situaciones y diálogos humorísticos, los que se desarrollan en forma independiente y simultánea. En este sentido, la arquitectura entrega también la estructura de la viñeta, creando unidades temáticas ais-

13 Renzo Pecchenino Raggi (1934-1988), conocido como Lukas, es autor, entre otros, de Apuntes Porteños (1971) y Apuntes Viñamarinos (1974), libros en que realiza acabados ensayos gráficos urbanos. 
ladas en ventanas, esquinas y calles, las que se unifican a través de un único paisaje urbano.

Tras su salida de El Pingüino, el nuevo equipo conformado por Hervi, Palomo, Pepe Huinca y Alberto Vivanco se abocará a La Chiva, una publicación en que, como ya señalamos, las temáticas urbanas así como la creciente politización de la sociedad chilena y la denuncia de las inequidades existentes serán centrales y donde el dibujante continuará incluyendo de manera esporádica «La ventana indiscreta». Ese mismo año congelará los estudios de arquitectura para dedicarse por completo al humor gráfico.

Posteriormente al paso por La Chiva, formará parte de La Firme pero su continuidad se verá truncada con el golpe militar de 1973, lo que significó la disolución de Quimantú y una fuerte persecución hacia el mundo cultural, por lo que el grupo de dibujantes se dispersó. Solo Hervi se quedó en Chile, viviendo de manera cercana el horror de la dictadura. Frente al férreo control de las publicaciones por parte del nuevo gobierno y la imposibilidad de continuar ejerciendo como humorista gráfico, en 1974 el dibujante retomará sus estudios de arquitectura para titularse al año siguiente.

Si bien alcanzó a ejercer durante algunos años como arquitecto «en muchos y muy variados proyectos: viviendas, poblaciones, mercados, industrias, minería, etc. Pero nada emblemático» (Vidal, entrevista), en 1977 volvió a su labor como humorista gráfico en la revista Hoy, publicación opositora al régimen militar. En un momento de reactivación producto de la liberación económica impulsada por el gobierno de Pinochet y de auge de la inversión inmobiliaria privada, tal como lo testimonian avisos publicitarios ${ }^{14}$ aparecidos en la revista Hoy, Hervi dio cuenta en sus viñetas de la vida cotidiana en edificios de gran altura y espacios habitables reducidos, de la precariedad de las construcciones y de la contaminación ambiental.

Sin embargo, hasta 1985 no retomará la estructura, aunque no el nombre de «La ventana indiscreta» a través de dibujos en que la ciudad se transforma en un marco

\footnotetext{
14 «Santiago es una ciudad que crece. Crece en número de habitantes, crece en tamaño, en potencialidad industrial, comercio y capacidad de sus servicios», señalaba un aviso del Banco de Concepción publicado en la revista Hoy en octubre de 1977.
}

para los diálogos de diversos personajes que comentan la contingencia política y económica. Si en los primeros momentos de la nueva de etapa de la serie abundan los globos de texto que provienen de alcantarillados y ventanas cerradas, sin que sea posible ver a su emisor (una opción que se puede leer como una estrategia de resguardo frente a la vigilancia de las fuerzas de orden $y$, por otra parte, como una necesidad de evidenciar hechos que se desarrollan lejos de la luz pública, especialmente atropellos a los derechos humanos), hacia 1988 la viñeta se transformó en un lienzo para, tanto a través de los diálogos como de la infraestructura urbana, mostrar el apoyo a la opción del No en el plebiscito de ese año que permitiría derrocar a la dictadura de Pinochet ${ }^{15}$ :

Cada vez que empezaba uno de esos dibujos lo hacía con mucho entusiasmo, porque ahí podía decir lo que pensaba, pero al llegar al séptimo u octavo chiste ya me sentía bastante amargado, porque junto a la satisfacción de hacer humor estaba el dolor de comprobar que sucedían cosas terribles. Lo bueno es que me permitía dibujar en la imaginación del lector-cómplice, lo que no se podía dibujar directamente (Vidal, entrevista).

No es el único cambio. Al comparar las diversas versiones de «La ventana indiscreta» se advierte un deslizamiento del horizonte que puede leerse también como un reordenamiento en la relación de los habitantes de la ciudad con respecto al poder y al espacio público. Mientras en El Pingüino la atención está puesta en los pisos superiores, en La Chiva, publicación que se autodenominaba como una «revista de humor horizontal», la calle es protagonista, y las situaciones que en ella se desarrollaban cobran importancia al tiempo que los ciudadanos ganan peso en la balanza política. Asimismo, durante la primera etapa en la revista Hoy, los personajes se repliegan en sus viviendas, o directamente desaparecen, en un contexto de ciudad vigilada propia de una dictadura, para volver a las calles cuando el regreso a la democracia se transforma en una posibilidad concreta.

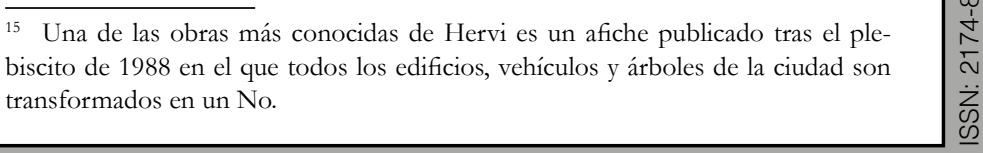


Este «movimiento de cámara» puede relacionarse también con los cambios en las políticas públicas urbanas entre 1960 y 1980. Tal como se ha señalado, el paso de un modelo desarrollista y de bienestar a un modelo basado en el libre mercado condicionó la forma de habitar la ciudad. Esta trayectoria espacial, como la denominan Aguirre y Rabí, se comprueba claramente en los cambios de objetivos de una institución como la Corporación de la Vivienda:

En una lectura global, podemos decir que gradualmente va desapareciendo el discurso contenido en el espacio público, al ser reemplazada la trama simbólica por una trama funcional. De la posición central que ha ocupado el tema del espacio público y su carga programática como estructura espacial de los proyectos iniciales, se pasa al relleno programático del espacio residual (público), de los loteos finales, en un desmembramiento de la cohesión inicial entre público y privado. Esta variación espacial conlleva una pérdida del discurso sobre el habitar popular y sobre el sistema residencial mínimo. La referencia pública sufre un descentramiento hacia el objeto - vivienda y hacia la vida privada como dimensión fundamental del habitar (Aguirre y Rabí, 89).

Tal como se advierte en los dibujos de Hervi y señala De Ramón, está situación solo comenzará a cambiar a partir de 1985 con la reorganización de las fuerzas opositoras al régimen militar.

\section{Arquitectura de una página: una mirada en torno a la espacio-temporalidad en ula ventana indiscretan}

Enrique Bordes, en las páginas iniciales de su Cómic, arquitectura narrativa, afirma que «el cómic podría ser considerado una arquitectura en sí mismo» (14), a partir de la idea que las historietas, en su ejercicio de puesta en página de los espacios, operan bajo modelos de construcción similares a los del arquitecto. Pero es claro que el cómic funciona bajo dos dimensiones bien definidas, una espacial y otra temporal (que a su vez se puede problematizar a partir de las nociones narratológicas de tiempo de la historia y tiempo del relato $\left.{ }^{16}\right)$. En efecto, el mismo Bordes luego señala que:

La estructura gráfica del cómic trata de lleno un problema que no es ajeno al arquitecto: representar (crear/pensar) un mundo y su espacio en las dos dimensiones del papel (o de una pantalla) (...) El dibujo del cómic va más allá, dado que, para narrar, debe jugar representando también el tiempo, una dimensión más (14).

De este modo, es indudable que tras el lenguaje del cómic, de aquel dibujo arquitecturado, están ancladas las nociones de un espacio/tiempo que se desenvuelve y articula de una manera particular. Pero, tal como indica Emma Martin Franco en su tesis Temporalidad en el Cine y en el Cómic: Fugacidady Eternidad, «¿Cómo plasmar el tiempo en un lenguaje que carece de movimiento, y que, por lo tanto, nos impide ver una acción en la totalidad de su desarrollo temporal?» (54). La unidad estructural mínima de un cómic se sitúa en una imagen fija (la viñeta) que se autosustenta o interactúa con otras para permitir construir la ilusión de un movimiento, de una acción continuada o del avance temporal.

Al respecto, Kai Mikkonen en su libro The Narratology of Comic Art (2017) señala que «perhaps the most obvious element for manipulating temporal order in comics is the panel relations that invite the reader to construct meaningful connections and fill in the gaps in information $(38)^{17}$, aspecto que se complejiza en obras como «La ventana indiscreta» de Hervi, donde la página completa (similar a una splash page) hace uso del recurso arquitectónico no solo para construir su espacio, sino del relato que carece de viñetas explícitas. Ahora, tal como Mikkonen afirma posteriormente, dichas transiciones no implican necesariamente un cambio temporal, ya que diferentes viñetas pueden estar mostrando el mis-

\footnotetext{
$\mathrm{Al}$ respecto, Kai Mikkonen en The narratology of comic art señala que «Specifically, the narratological distinction between story-time (the chronological order of the events) and discourse-time (the order in which these events are presented in the comic) allows us to investigate the basic forms of temporal structure in comics» (Mi33) [específicamente, la distinción narratológica entre tiempo de la historia (el orden cronológico de los eventos) y tiempo del relato (el orden en el cual los eventos son presentados en el comic) nos permiten investigar las formas básicas de estructura temporal en las historietas].

«quizás el elemento más obvio para manipular la ordenación temporal en el cómic es la relación entre paneles que invita al lector a construir conexiones significativas y llenar los vacíos de información.»
} 
mo momento desde diversos puntos de vista, lo que enriquece la percepción del lector/a en torno a un mismo acontecimiento (aspectos que luego analizaremos). En cierto modo, forzando el proceso podríamos asimilarlo de alguna forma a lo que Scott McCloud definirá en Entender el cómic. El arte invisible como Closure o clausura (63), es decir, un fenómeno metonímico que permite observar las partes pero percibirlas como un todo en lo que será la noción de un continuo o una realidad unificada. Ahora, este fenómeno no sólo se producirá en una relación de viñeta a viñeta, sino que puede ser articulada en las relaciones de los diversos elementos página a página.

Es por esto que para comprender mejor las nociones del tiempo (y espacio) en la historieta, deberíamos fijarnos en algunas concepciones provenientes desde la narratología. En primer lugar, establecer la idea de un tiempo lineal, secuencial y articulado, y otro estéticamente configurado por el autor o autora (la distinción tiempo de la historia/tiempo del relato), es en cierto modo irrelevante para el cómic, dado que la puesta en página de los acontecimientos o acciones así como de los espacios representados en las viñetas siempre invitan al lector/a a una reconfiguración de la disposición
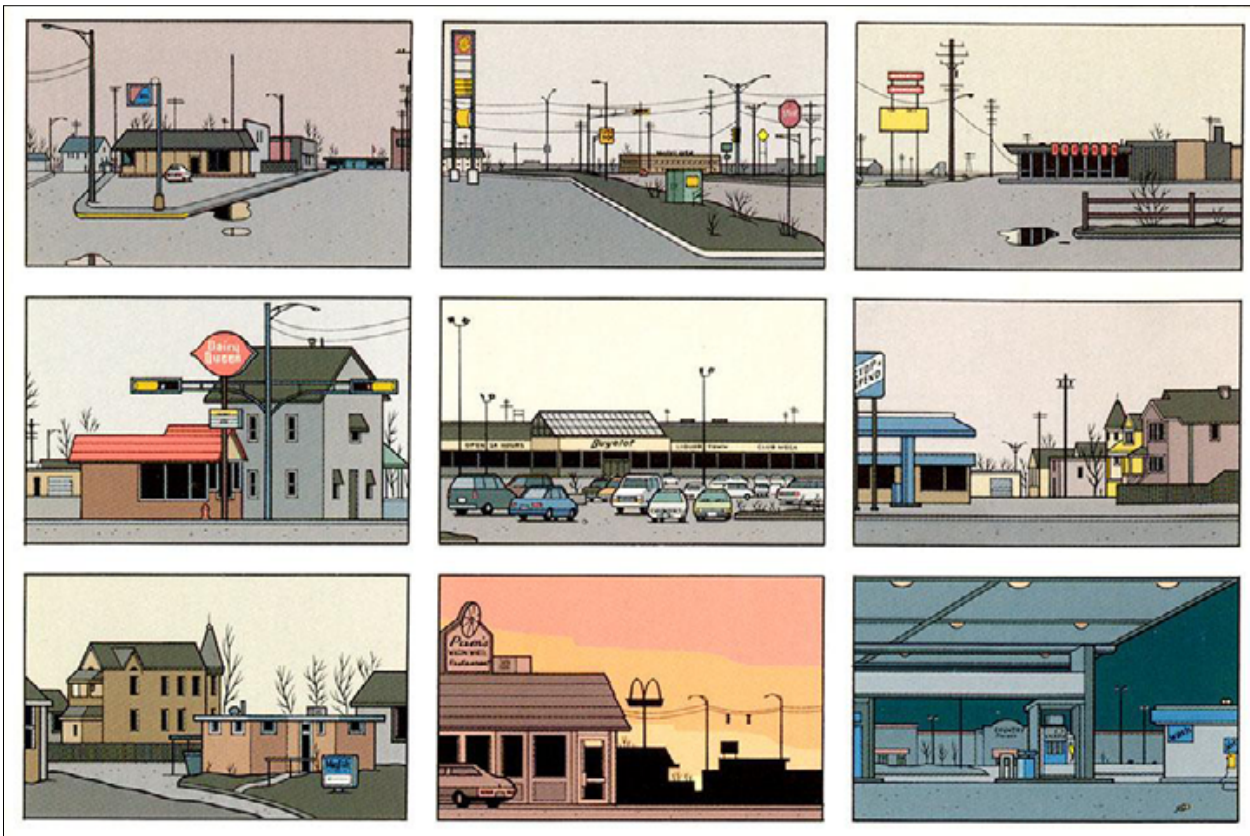

temporal. Este hecho es evidente en ejemplos contemporáneos como los de Chris Ware (fig.7), en donde el panel no sigue los patrones tradicionales de lectura del cómic, lo que termina complejizando los procesos lectores pero a su vez amplia las posibilidades de aprehender la realidad, comprendida por tiempo y espacio, de una manera fragmentaria y relativa.

No obstante, en trabajos como «La ventana indiscreta» podemos observar un juego inverso, en donde el espacio único representado puede llevar al efecto de un tiempo unificado, aunque las situaciones representadas puedan estar ocurriendo simultáneamente o en momentos diferenciados.

En ese sentido, podríamos concebir al cómic, no como un conjunto de viñetas secuenciado, en un proceso lineal y cerrado, sino más bien como un entramado temporal, en donde cada cuadro, cada plano, implica un proceso de tiempo ampliado, pero que debe ser reconstituido en el proceso de lectura. Como afirma Franco, «la temporalidad en el cómic, se podría decir que se puede sintetizar a partir de la dicotomía espacio-tiempo y montaje-ritmo» (62) para luego agregar que «el tiempo está siempre presente de forma visual en el cómic: en una única plancha encontramos un tiempo pasado, un tiempo presente y un tiempo futuro» (ib).

Desde dicha perspectiva, la imagen fija como un punctum temporis, es decir, la representación de un instante en el tiempo que se abre y convierte a la viñeta, permite releer la imagen fija que abre un canal, un espacio en el tiempo, intensificando en el lector/a la relevancia de un momento. Pero el juego de diálogo no sólo se establece en la comunicación intrínseca de viñeta a viñeta, sino que como

Fig.7 Panel de Jimmy Corrigan, the smartest kid on earth (2004. Sin numeración), de Chris Ware. 
indica Mercedes García Peñalba en su artículo «La temporalidad en el cómic»:

La viñeta, por sí sola, expresa matices temporales no solo en el plano visual (i.e. el juego cinético favorece la distribución de los personajes), sino también en el plano verbal. La palabra escrita dilata la temporalidad, en términos de percepción lectora, mediante mecanismos de cohesión interna en la didascalia (sin cartucho) y en los globos de texto, que sugieren una secuencia interna (698).

Por lo tanto, la tarea del lector o lectora está en un proceso de lectura implícita, donde deberán ir completando aquellos espacios intersticiales de tiempo que la viñeta y su puesta en página ofrece. Del mismo modo, Neal Cohn en su artículo «The limits of time and transitions: Challenges to theories of sequential image comprehension» señala:

Instead it is about the basic comprehension of sequential images - comparable to the creation of meaning by words in sentences. While we are consciously aware of (sometimes various) meanings of sentences, the unconscious processes that motivate these understandings remain inaccessible. The comprehension of sequential images is taken to work in the same way» $(129)^{18}$.

Es decir la comprensión básica de la estructura de las imágenes secuenciadas en el cómic se basa en operaciones conscientes e inconscientes por parte de los lectores, a partir del reconocimiento de todos sus elementos constituyentes.

Todo esto nos hace pensar que la cuestión del tiempo y el espacio en el cómic es central dado su manera de comprender y estructurar la realidad a través de las viñetas, cosa que, como en un cronotopo bajtiniano, termina impactando todas las esferas de su constitución. En ese sentido, es interesante el espacio del gutter o calle como aquel lugar intersticial que clausura un espacio de tiempo para vincularlo con otro. En ese milimétrico momento, el devenir de la secuencia del cómic se quiebra. Es esa la fractura del tiempo, he ahí como

\footnotetext{
18 «En cambio, se trata de la comprensión básica de imágenes secuenciales - comparable a la creación de significado por palabras en oraciones. Mientras somos conscientes de (a veces varios) significados de oraciones, los procesos inconscientes que motivan estos entendimientos permanecen inaccesibles. La comprensión de imágenes secuenciales es llevada a trabajar de la misma forma».
}

unidad mínima, como principio regulador, la noción de un momento que puede ser manipulado y dislocado, sin embargo, ¿cómo interpretar este fenómeno cuando el gutter no está explícitamente incorporado?

Ahora, podríamos coincidir con Thierry Groensteen quien en Système de la bande dessiné (1999) entiende al cómic como un entramado o sistema complejo, en donde la articulación espacial de viñetas establece procesos de acoplamiento que van más allá de la pura secuenciación de una a otra, en una cadena lógica de acontecimientos, sino que presupone en el montaje de la página una intencionalidad más profunda. Esto es lo que permite la vinculación entre diversas viñetas, lo cual potencia el efecto de una desestructuración de la temporalidad, incluso en aquellas historietas que carecen de viñetas, estableciendo en algunos casos a la página como una unidad narrativa de construcción de significado. El mismo Groensteen afirma que, «toute image dessinée s'incarne, existe, se déploie dans un espace ${ }^{19}$ (25), para luego añadir, «mettre en relation des vignettes de bande dessinée, c'est donc, nécessairement, mettre en relation des espaces, opérer un partage de l'espace» ${ }^{20}$ (25-26). Veamos cómo se despliega este principio en este capítulo de «La ventana indiscreta» (fig. 8):

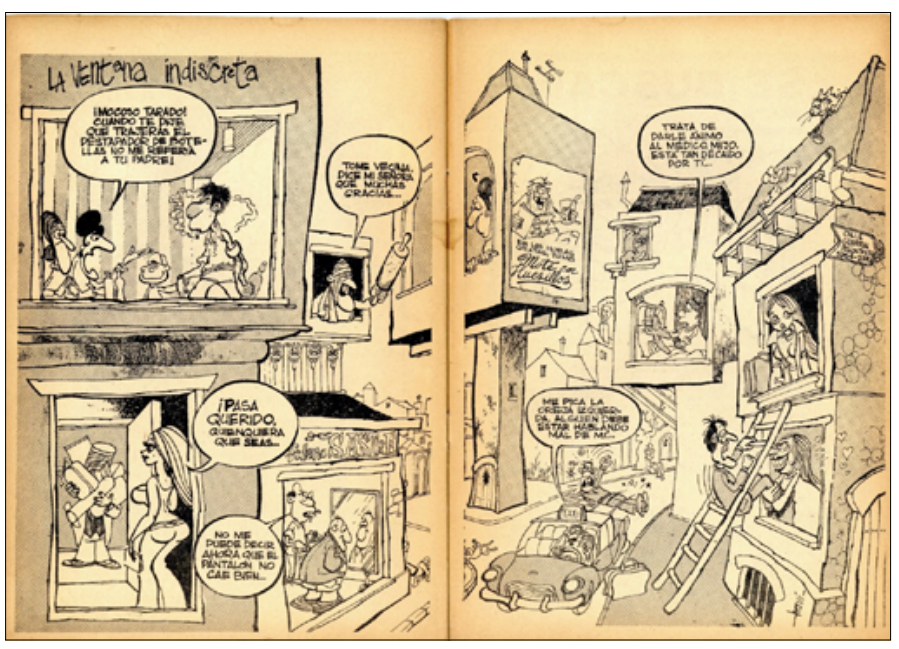

Fig.8 «La ventana indiscreta». Aparecido en La Chiva, número 22 ( $\sin$ año ni fecha)

\footnotetext{
«Toda imagen dibujada se encarna, existe, se despliega en un espacio».

«Poner en relación las viñetas de la historieta es pues, necesariamente, poner en relación espacios, operar una repartición del espacio».
} 
En ella podemos ver claramente el procedimiento de construcción de una de tantas versiones de la serie. La realidad de la urbe es desplegada a través de su arquitectura, la cual a su vez funciona como soporte estructural de la propia historieta. Hablamos de un ejercicio de ida y vuelta, en donde la ciudad (y sus movimientos) impactan al autor, y este a su vez la devuelve en la página. Tal como en la película de Hitchcock, cada ventana es un mundo, y este recurso es aprovechado por Hervi para transfigurarlas en viñetas donde se despliegan cada uno de los chistes. Sin embargo, volvemos nuevamente a la idea de una condición metonímica de las imágenes dentro de la historieta, que se sumaría a la fragmentación propia de las elipsis producidas por las viñetas-ventanas. Esta comprensión de cada parte como un todo genera un efecto relevante para el lector o lectora, ya que esto le permite condensar todo el tiempo en un momento, como en esta clásica plancha de Gasoline Alley (fig.9).

La propiedad metonímica de la composición de la página de historieta, en donde cada viñeta condensa

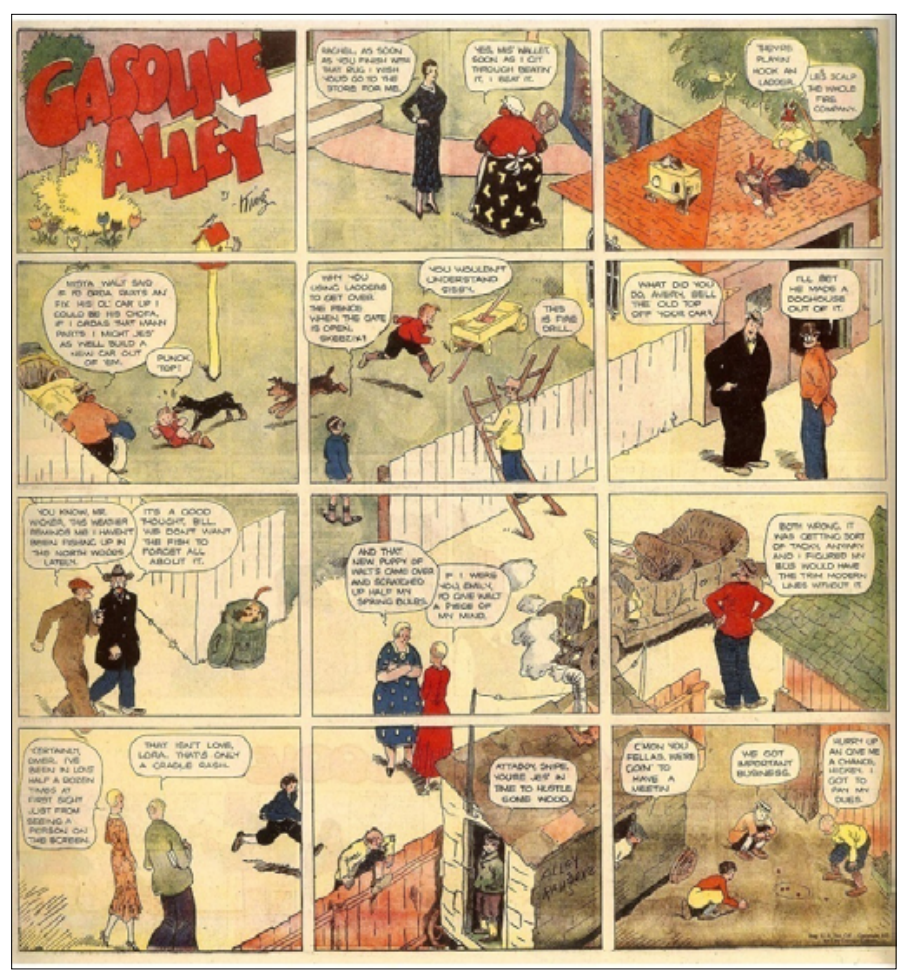

Fig.9 La distinción de un tiempo simultáneo, ya puede ser vista en esta página de Gasoline Alley de Frank King, publicada el 24 de mayo de 1931. en sí mismo un lapso de tiempo que luego se sumará a otros para dar la percepción de un todo articulado, es la que finalmente permite aprehender la compleja realidad multiforme de un hecho representado, en este caso, el caos mismo de la propia ciudad. Será a través de la idea de un closure de McCloud, o la noción de artrología en Groensteen, la forma en que de imagen a imagen, viñeta a viñeta, los lectores y lectoras podrán restablecer procesos complejos de construcción de significado. En este caso, Hervi propone una curiosa paradoja en donde la doble página se plantea no solo como una composición historietística compleja, sino que a través del sinsentido representado intenta dar coherencia a una ciudad incoherente. La página logra reconfigurar el caos diario, y el humor permite hacer llevadero aquello que a ratos puede ser incomprensible.

Enrique Bordes señala que «la función narrativa está íntimamente ligada a la historia de la arquitectura» (249). En las páginas de «La ventana indiscreta», Hervi aprovecha el espacio de la ciudad y sus construcciones como un motivo narrativo. $\mathrm{Al}$ situarnos como voyeurs nos hace partícipe de lo público, pero también de lo privado. Vemos situaciones de violencia cotidiana, chistes pícaros, e incluso referencias políticas, como el nombre de la calle y su numeración: «General descontento. 1964-1970». También en una de las ventanas-viñeta incorpora un elefante que será recurrente en esta historieta. En ese sentido, podríamos asumirlo como un cómic de concepción teatral, con sus escenarios, personajes y escenas bien definidas. Ahora, «La ventana indiscreta» no emergerá en La Chiva, sino que, como ya sabemos, tendrá un recorrido previo en la revista El Pingüino (fig. 10 y 11). En algunas de estas páginas podremos ver cómo el sinsentido de las situaciones retratadas, se ve reforzado por la misma composición de la página, donde edificaciones confusas y a ratos imposibles dan cuenta de una urbe siempre en crecimiento descontrolado e improvisado y en donde sus habitantes interactúan de formas inesperadas. Incluso en algunas podemos ver espacios más «experimentales» con la incorporación de técnicas como el collage. 


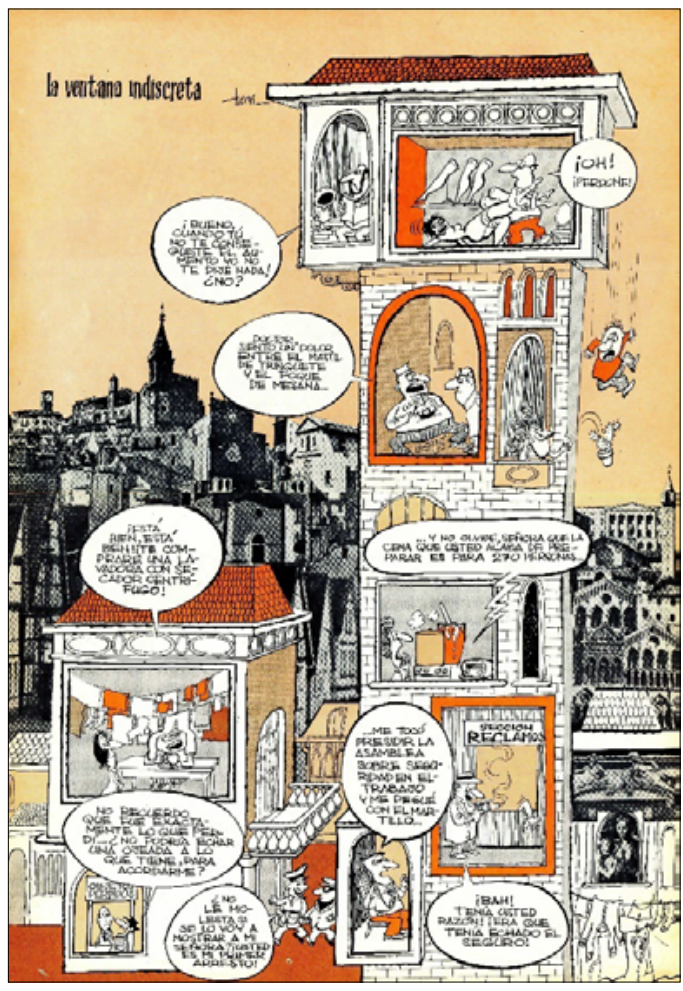

Fig.10 Aparecida en El Pingüino, número 531

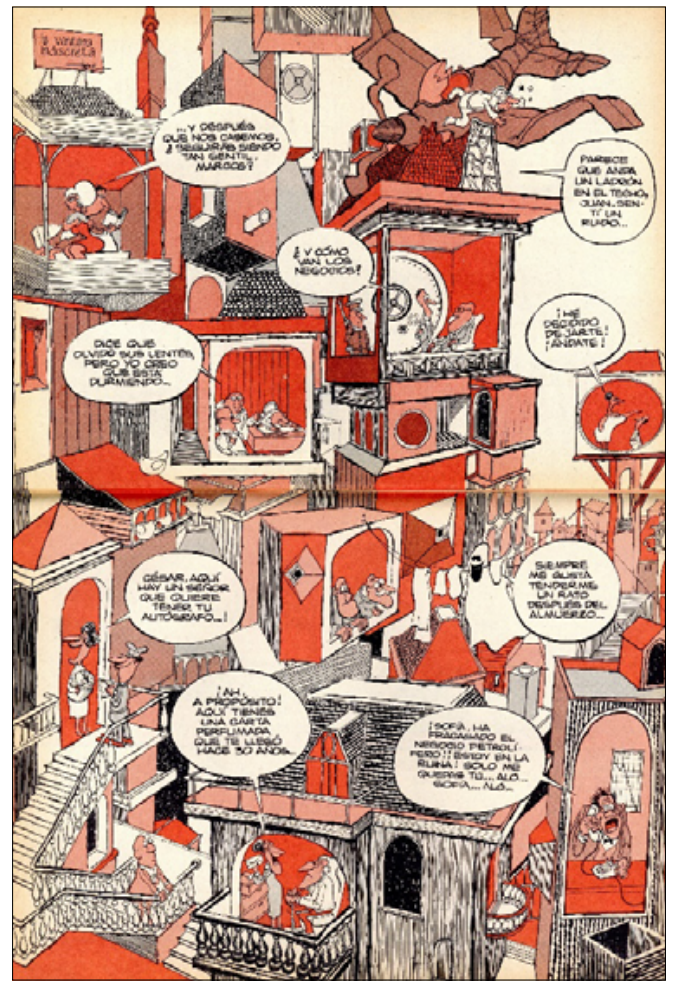

Fig.11 Aparecida en El Pingüino, número 544
Ahora, antes de cerrar este acercamiento a la idea del tiempo y el espacio, y como esta se manifiesta en una obra como «La ventana indiscreta», sería importante incorporar la figura del lector. En este caso, no solamente se ve interpelado por el contenido de la obra, sino que a diferencia de otros medios como el cine o la obra musical, donde el tiempo del espectador es impuesto, el tiempo del lector en el cómic está sujeto a quien lee, lo cual también termina impactando el tiempo de la misma obra y su interpretación. Es lo

A través de sus diversos episodios, Hervi despliega una serie de recursos arquitectónicos, tales como alzados y fachadas, ventanas, entre otros, los que se van incorporando a la historieta y le dan forma, mutando en viñetas para el lector. Incluso, en algunos casos, el motivo espacial de la ciudad permite transformar la doble página en un ejercicio metatextual, como en este ejemplo del número 24 (fig. 12) en donde se nos muestran las «oficinas centrales» de La Chiva, y todas las situaciones retratadas aluden a la revista, tales como sus lectores, críticas a la «competencia», las consecuencias de su lectura, o la precariedad de la misma publicación.

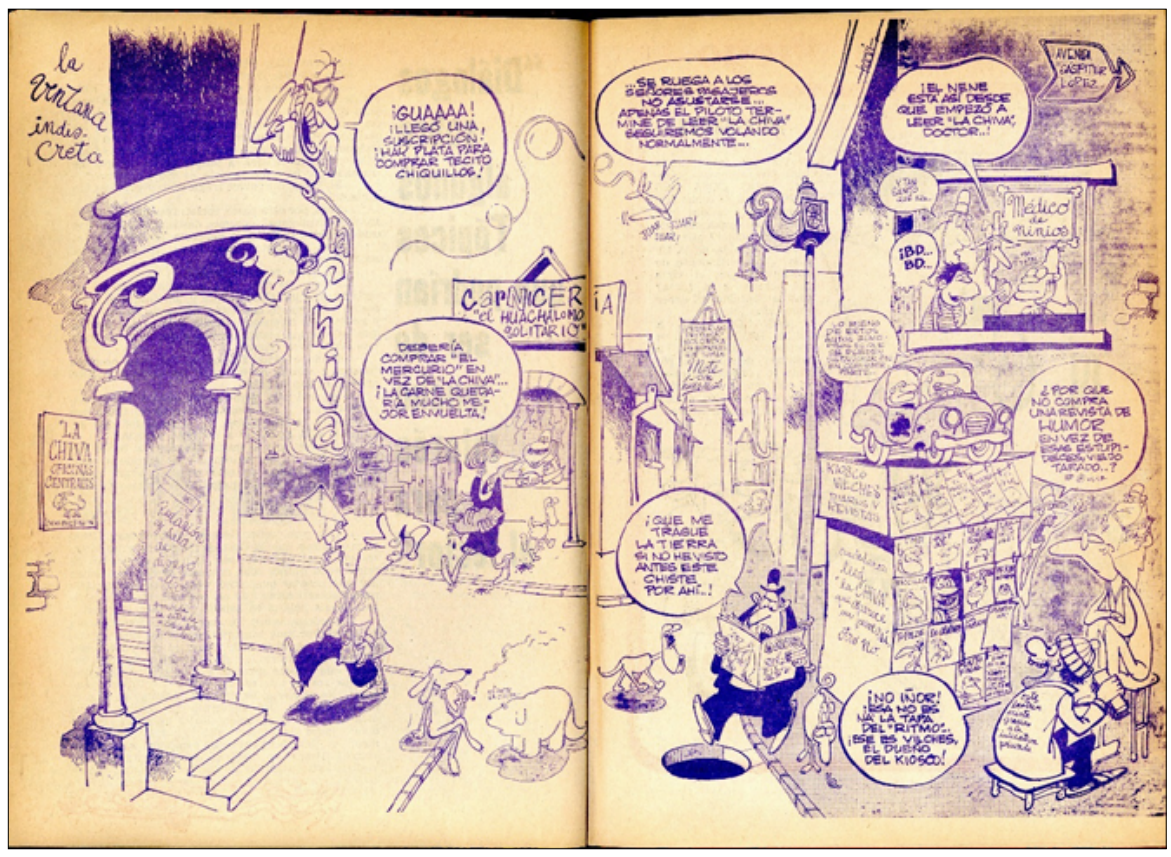

Fig.12 Aparecida en La Chiva, número 24 (sin año ni fecha) 
que Daniele Barbieri en Los lenguajes del cómic indica como «tiempo de lectura», que «no debe considerarse como el tiempo efectivo que emplee cada lector en leer una viñeta $(. .$.$) debe considerarse más bien como$ un tiempo medio, o un tiempo ideali (243). En este sentido, a la temporalidad interna de la obra asignada por el autor o autora, en el binomio narrativo Tiempo de la historia/Tiempo del relato, se añade la temporalidad del propio lector o lectora, quien asimila el juego que le sugiere la página de historieta como un modelo de reconstitución de un devenir histórico. En el caso particular de «La ventana indiscreta», este tiempo de lectura es central ya que justamente la obra nos propone ser observadores detallados de la realidad. Claramente, el acto del voyerismo tiene su propio tiempo personal.

\section{Algunas breves conclusiones}

A lo largo de este artículo, pudimos ver como una publicación icónica como La Chiva fue capaz de hacerse cargo, desde la historieta y el humor, de conflictos sociales que hasta el día de hoy aquejan a Chile y, por qué no decirlo, a muchos países latinoamericanos. Por otro lado, centrando nuestro trabajo en la figura de Hervi y su obra «La ventana indiscreta», pudimos discutir brevemente el potencial de la historieta para representar la sociedad y sus problemas, haciendo uso además de otros códigos, como el lenguaje arquitectónico que acabará cumpliendo una doble función dentro de la obra como espacio figurativo y simbólico.

Lamentablemente, dada la extensión de este texto, solo pudimos escarbar una parte ínfima, tanto del trabajo realizado por los autores en La Chiva como de la obra de Hervi. En ese sentido, quedan fueran historietas relevantes como Artemio, el trabajo del resto del equipo como Pepe Huinca, Pepe Palomo o el mismo Alberto Vivanco, etc. Por otro lado, solo fueron posibles de abordar algunos ejemplos acotados de «La ventana indiscreta» en sus dos primeras encarnaciones, dejando pendiente su evolución posterior en revista Hoy.
Del mismo modo, consideramos que esta relación de historieta, arquitectura y conflictos sociales es permanente dentro de la historieta y el humor gráfico en Chile. Queda incompleto el camino sin considerar el paso de $L a$ Chiva hacia La Firme. Asimismo, queda la puerta abierta para un trabajo comparativo entre «La ventana indiscreta» $\mathrm{y}$ «Sentido del rumon», página de humor gráfico publicado en plena dictadura y desarrollado por Jorge Montealegre, y el dibujante tristemente fallecido, Eduardo de la Barra.

Sin embargo, estas miradas aplazadas dan cuenta de un campo siempre en expansión. Esperemos que este artículo sirva como el inicio de un largo camino, uno que necesitamos recorrer.

\section{Bibliografía}

Aguirre, B., Rabi, S. «La trayectoria espacial de la Corporación de la Vivienda (CORVI)». Revista Electrónica DU\&P. Diseño Urbano y Paisaje. 18 (VI), 2009. Centro de Estudios Arquitectónicos, Urbanísticos y del Paisaje. Universidad Central de Chile Santiago, Chile. Diciembre 2009. Consultado en http://dup. ucentral.cl/pdf/18_trayectoria_espacial_b.pdf

Barbieri, Daniele. Los lenguajes del cómic. Barcelona: Paidós, 1993.

Bordes, Enrique. Cómic, arquitectura narrativa. Madrid: Cátedra, 2017.

Cardoso, Armindo. «Población callampa, Santiago de Chile 1971». Archivo Fotográfico. Disponible en Biblioteca Nacional Digital de Chile http:/ /www.bibliotecanacionaldigital.gob.cl/bnd/637/w3-article-156309.html

Cohn, Neil. «The limits of time and transitions: Challenges to theories of sequential image comprehension». En Studies in Comics, 1(1), 2010

De Ramón, Armando. Santiago de Chile (1541-1991): Historia de una sociedad urbana. Santiago: Catalonia, 2018.

Espinoza, Vicente. Para una historia de la ciudad de los pobres. Santiago: Ediciones SUR, 1988.

Garcés, Mario. Pan, trabajo, justicia y libertad. Las luchas de los pobladores en dictadura (1973-1990). Santiago: Lom Ediciones, 2019. 
García Peñalba, Mercedes. Signa, 23, 2014, pp. 687-713. Mundt, Tito. Guia bumorística de Santiago. Santiago: Zig-

Groensteen, Thierry. Système de la bande dessinée. Paris:

Presses Universitaires de France, 1999.

King, Frank. "Gasoline Alley. Sunday newspaper comic, 24 de mayo de 193». Masters of American Comics. Paul

Karasik. United States: Yale University Press, 2005.

Martin Franco, Emma. Temporalidad en el Cine y en el Cómic: Fugacidady Eternidad [Tesis de máster]. Barcelona: Facultutat de Gegrafia i Història, 2016. Consultado: http:/ / diposit.ub.edu/dspace/bitstream/2445/ 103313/1/TFM\%20Martin\%20Franco.pdf

McCloud, Scott. Entender el cómic. El arte invisible. Bilbao: Astiberri, 2019.

Zag, 1966.

Palomo, José y Hernán Vidal, Alberto Vivanco y Jorge Vivanco. La Chiva. Santiago de Chile: autoedición, 1968-1970.

Salazar, Gabriel. Movimientos sociales en Chile. Trayectoria bistórica y proyección política. Santiago, Chile: Uqbar Editores, 2012.

Vidal, Hernán. Arquitectura e historieta. Entrevista inédita con los autores. Enero de 2021. Vía e-mail.

Vidal, Hernán, Carlos Reyes, Rodrigo Salinas y Rodrigo Dueñas, ed. La Chiva, ;Y qué jué! Santiago de Chile: Feroces editores, 2011.

Mikkonen, Kai. The narratology of comic art. New York: Vivanco, Alberto (dir.). El Pingüino. Santiago de Chile: Routledge, 2017.

Montealegre, Jorge. Hervi, desde Chile. Alcalá de Henares: Instituto Quevedo de las artes del humor, 2019. Editorial Lord Cochrane. Sin año. Números 531 y 544. Ware, Chris. Jimmy Corrigan, the smartest kid on earth. United States. Pantheon, 2003. 